\title{
Customizable Knowledge Portals for Teaching
}

\author{
I.T. Hawryszkiewycz \\ University of Technology, Sydney
}

igorh@it.uts.edu.au

\begin{abstract}
The paper describes knowledge portals as providing services that can be customized to a variety of learning environments. It defines portals to be made up of three main components, a community of practice, a body of knowledge, and services to maintain the body of knowledge. The body of knowledge is organized around a knowledge map, which can be accessed through a number of services. The services support a general learning process, which is defined using knowledge sharing as grounded theory. The communities can be organized for different environment. The paper describes the services needed to support a general learning process including collaboration, knowledge evolution and illustrates them with an example in a learning environment.
\end{abstract}

Keywords: Learning Process, Collaboration, Portals, Knowledge Sharing, Web-based learning

\section{Introduction}

Learning communities are now beginning to take many forms. There are the conventional classroom situations, but increasingly we are beginning to see new forms such as work based learning, distance learning, and just-in-time learning in business processes. Increasingly web based technologies are being used to support these learning environments. The question is how to use web-based technologies to deliver higher quality outcomes at lower cost. Much earlier work concentrates on supporting particular activities of the learning process and does not integrate them into a learning process. For example, Neal (1997) has carried out work on using web technologies in distance teaching emphasizing the delivery of materials.

The goal, however. is to support all the activities found in learning and integrate them into a learning process. . There has been some work in describing the kinds of support for each activity. Wade and Power (1998) and Shank (1998) have outlined a number of requirements for computer supported learning systems and described alternate technologies for supporting learning activities. However, much of this suggests different technologies for different activities. Our goal is to provide a unified interface that can be used to support all learning activities in an integrated way. A further goal is to define the services that can be combined in flexible ways to support different learning environments. The paper addresses this goal by first defining a generic learning process and its activities. It then proposes that knowledge portals can be used to support the activities and combine them to support different ways of learning.

Material published as part of these proceedings, either on-line or in print, is copyrighted by Informing Science. Permission to make digital or paper copy of part or all of these works for personal or classroom use is granted without fee provided that the copies are not made or distributed for profit or commercial advantage AND that copies 1) bear this notice in full and 2) give the full citation on the first page. It is permissible to abstract these works so long as credit is given. To copy in all other cases or to republish or to post on a server or to redistribute to lists requires specific permission from the publisher at publister@intormingscience.org
The learning process is defined in this paper using Nonaka's (1994) model as grounded theory. The learning process is defined as a set of activities carried out to acquire specific knowledge in some domain. Different web services can be provided through knowledge portals to support the learning activities. Portals should allow the service to be customized to different learning needs and integrated into a learning process. Portals should go 
beyond supporting selected activities but be more broadbased allowing their body of knowledge to evolve and for communities to create such new bodies of knowledge.

To do this, it is proposed that portals integrate collaborative services with learning services. The collaborative interface can be used to structure communities and assign different portal responsibilities and artifacts to different members of these communities. A knowledge map is used to assist students to sequence their learning process. The portal should provide services to construct the knowledge map using subject ontologies (Maedche and Staab, 2001). A prototype system, called LiveNet, is used as an example of such a portal and an example of its use in teaching is given.

\section{The Learning Process}

Our approach is to develop a framework for describing the learning process uses the work of Nonaka (1994) as grounded theory. Nonaka sees knowledge sharing and creation follows the process shown in Figure 1.

Nonaka's process includes four phases. The first phase is socialization where people bring together their experiences and share insights in an area. This can result in new relationships or introduction to new concepts and ideas that can be followed through in later steps. The next step, externalization, is where some of this captured expertise is interpreted into a form that can lead to some actions. The discussions now become more focused with specific issues being addressed and new ideas generated. The ideas are then combined where necessary with existing information and then

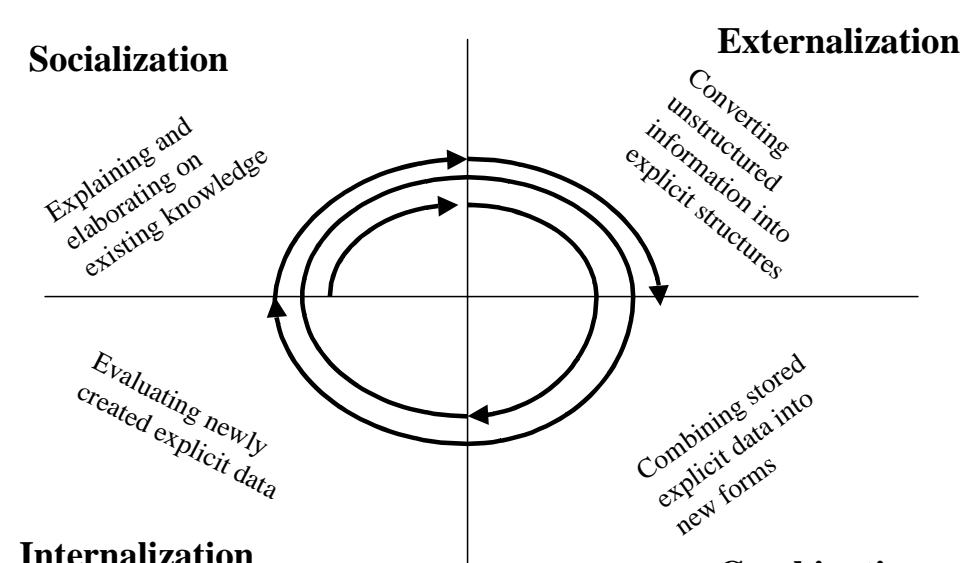

Internalization

Combination

Figure 1 - Nonaka's knowledge creation process applied in practice during internalization. Any outcomes of any actions evaluated in further socialization and the cycle is repeated. Nonaka goes further and defines the environments under which knowledge sharing can effectively take place. He suggests that knowledge is only meaningful within a context and its environment. The context defines the relevance of what is discussed and provides the basis for any interpretations. Nonaka defines four different kinds of environments to match his process. These are:

- Socializing - requires easy ways to exchange experiences, develop trust, share values

- Dialoging - sharing of mental models, articulation of concepts, development of common terms. Usually consciously constructed.

- Systemising - requires ways to visualize interactions, constructing artifacts, combine explicit knowledge.

- Exercising - communicate artifacts and embody in working context. Reflect on outcomes.

\section{Learning Activities Defined in Terms of Nonaka's Process}

This learning process is shown in Figure 2. The process is made up of four learning activities, which are described in detail in Table 1, which also describes the relationship of learning activities to Nonaka's process and implications on agent activities. The agent in these activities is usually the teacher, but there 


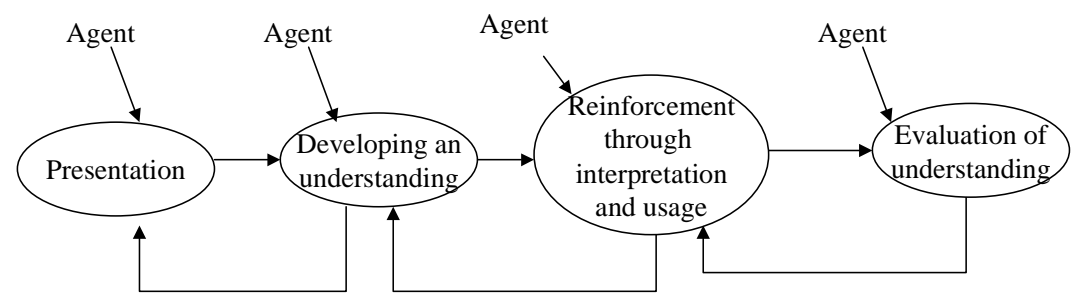

Figure 2 - Activities in the Learning Process

are other possibilities such as tutors or other assistants. They can also be software agents. The goal is to improve processes by reducing agent costs or support them with better tools.

\begin{tabular}{|l|l|l|l|}
\hline Learning Activity & $\begin{array}{l}\text { Relationship to Nona } \\
\text { model }\end{array}$ & $\begin{array}{l}\text { Environmental requ } \\
\text { ments }\end{array}$ & Implications for portals \\
\hline Presentation & $\begin{array}{l}\text { Socialization and presenta- } \\
\text { tion of important concepts. }\end{array}$ & $\begin{array}{l}\text { Easy ways to exchange } \\
\text { experiences, which can be } \\
\text { readily implemented with } \\
\text { potential cost reductions. } \\
\text { Distribution of materials. }\end{array}$ & $\begin{array}{l}\text { Access to presentations or } \\
\text { explanations. Can be done } \\
\text { using the WWW. Requires } \\
\text { ways of presentation that } \\
\text { clearly identify important } \\
\text { issues. Use of discussion } \\
\text { databases for socialization. }\end{array}$ \\
\hline $\begin{array}{l}\text { Developing an under- } \\
\text { standing of the con- } \\
\text { cepts }\end{array}$ & $\begin{array}{l}\text { Externalization through } \\
\text { looking at examples and } \\
\text { trying things out. }\end{array}$ & $\begin{array}{l}\text { Sharing of mental models, } \\
\text { articulation of concepts, } \\
\text { development of common } \\
\text { terms. }\end{array}$ & $\begin{array}{l}\text { Requires interaction through } \\
\text { feedback from experts and } \\
\text { reinforcement through dis- } \\
\text { cussion or other feedback } \\
\text { from agents. }\end{array}$ \\
\hline Reinforcement & $\begin{array}{l}\text { Continued interpretation } \\
\text { with experimentation. } \\
\text { Trying things out. Seeing } \\
\text { how things work. Compar- } \\
\text { ing with explicit forms. }\end{array}$ & $\begin{array}{l}\text { Reinforcement though in- } \\
\text { terpretation and usage } \\
\text { visualizing interactions, } \\
\text { constructing artifacts, } \\
\text { combine explicit knowl- } \\
\text { edge. Interact for evalua- } \\
\text { tion }\end{array}$ & $\begin{array}{l}\text { Extension of the above with } \\
\text { easy access to previous ex- } \\
\text { amples and their interpreta- } \\
\text { tion in the current situation. }\end{array}$ \\
\hline Exercising & $\begin{array}{l}\text { Internalization by getting } \\
\text { evaluations of experiments. }\end{array}$ & \begin{tabular}{l} 
Get feedback on outcomes. \\
\hline
\end{tabular} & $\begin{array}{l}\text { Better ways to evaluate out- } \\
\text { comes. }\end{array}$ \\
\hline
\end{tabular}

Table 1 - Learning in Nonaka's terms

\section{Combining Medium and Process}

The way learning proceeds through this process requires different interaction and media at different learning activities. These are often determined by two other dimensions, shown in Figure 3. One is whether support is to be based on codification or personalization. In codification the emphasis is on storing knowledge in explicit form and providing the tools for learners to learn primarily through interaction with the codified knowledge base. In personalization there is more emphasis on personal interaction. The simplest example is that of delivery of materials. With codification there is emphasis on overheads, animation and on-line experimentation. In personalization the emphasis is on face-to-face lectures. Usually codification uses asynchronous and less costly methods, whereas personalization requires synchronous communication. 
The other dimension depends on whether learning is objectivist or constructivist (Leidner and Javerpaa, 1995). The simplest difference is that here the learner studies concepts and needs to find ways to understand them. In constructivist learning the emphasis is on process or best ways to do things. Examples are ways construct artifacts. The emphasis here is often on groups and learning often takes place through group interaction. Thus here students learn design guidelines, how to respond to different situations. Often this is most relevant to business processes. Thus portals must be able to provide the workspace and media to support chosen interactions.

Our goal is to provide portals to support a variety of interaction styles. It is to cover the entire space of Figure 3, providing the necessary process support as well as the media to use at each activity while integrating them in a seamless way.

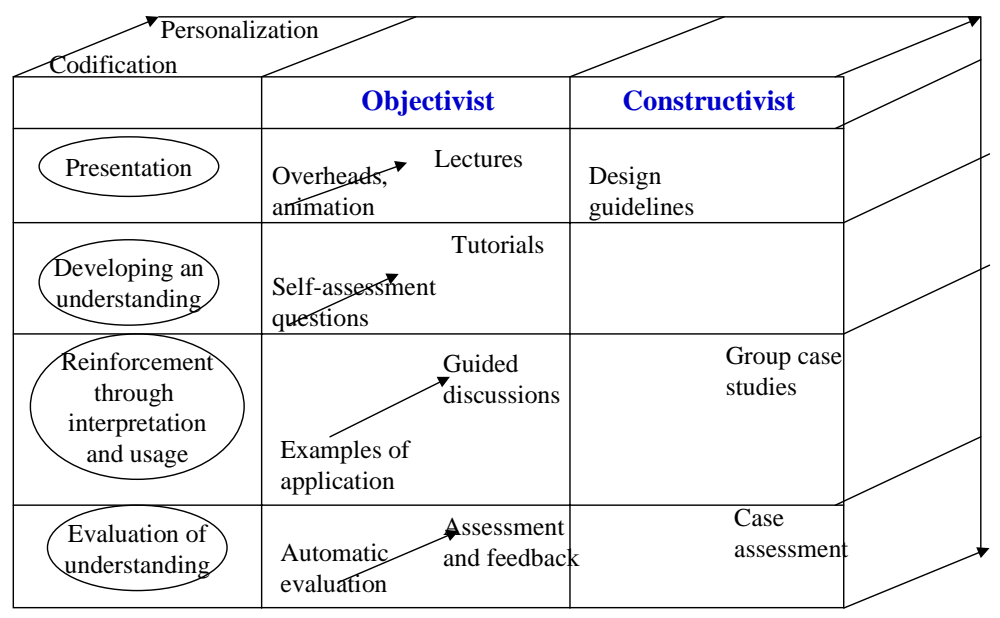

Figure 3 - Media Selection

\section{Portals for Learning}

The goal is to provide the services needed to support all the activities shown in Figure 3. The portal structure proposed here is illustrated in Figure 4. It is described in three dimensions. These are the community of practice, the body of knowledge and the services provided to the community of practice. As shown in Figure 4 these bodies of knowledge are maintained collaboratively by a number of teachers. Services are provided to learners. This gets away from the traditional way where individuals create material independently and present it as needed. What we are now looking is a collaborative group of knowledge workers, who may be a group of consultants or groups of academics, developing a body of knowledge often known as a knowledge center.

\section{The Community of Practice}

The community of practice can include a variety of roles. In most learning environments there are simply teachers and learners. These can be expanded to include tutors or assistants that work together with the teacher. In more elaborate environments, there can be owners, experts, novices or apprentices as well as a variety of users. We also propose that there can be some advantage in teachers forming centers that develop bodies of knowledge that may be packaged in different ways for different courses. These can also include external experts for evaluating adding to the body of knowledge. 


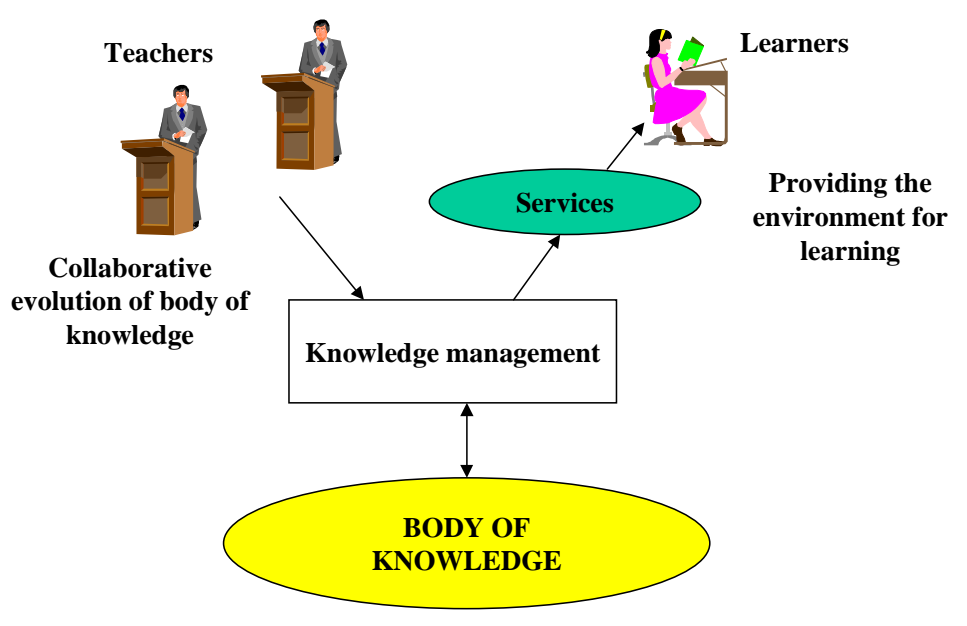

Figure 4 - The knowledge portal

\section{Body of Knowledge}

The body of knowledge is generally organized around an ontology for the appropriate domain. Apart from the ontology of concepts the body of knowledge also includes exercises and solutions, exams, case studies and other study material. As an example Figure 5 shows the structure of the body of knowledge for teaching ebusiness systems.

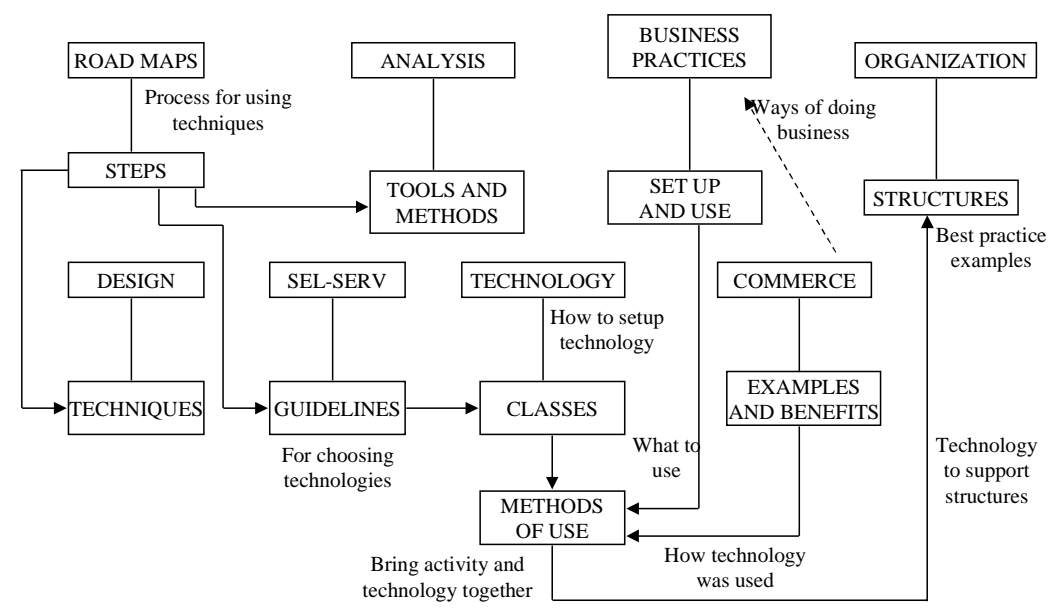

Figure 5 - Structuring the Knowledge

Each rectangle in Figure 5 represents a set of similar concepts. Lines show the relationships between the concepts. Thus the technologies box will contain classes such as workflow, document management or discussion database. Business practices may contain concepts such as decision-making, knowledge sharing or brainstorming. The method of use will include concepts of how to use the technologies in the different business practices.

The concepts are usually entered into a knowledge map that serves as an initial entry point for learners. The relationships between the concepts can then guide students through a study pattern (Fischer, 2001). Thus some students can start with a commerce application or business practices, see what it does and then follow through to technologies useful for the application. Others may start with the technology and follow it through to potential applications. 


\section{The Services}

Figure 6 shows a more detailed structure of the services to be provided by the portal. It includes services to maintain a knowledge map that is the prime point of access to the body of knowledge. The knowledge map itself can include terms to support objectivist learning as well as guidelines for processes for constructivist learning and for collecting information on experiences within processes. The body of knowledge includes facts as well as processes and suggestions how to carry them out. It includes ways for owners to refine the body of knowledge.

Figure 6 also includes feedback from learners to refine the body of knowledge. Such feedback can be either codified as for example through discussion databases or personalized through face to face interaction. During such feedback messages are received about experiences in self-learning. These can be analyzed and sorted and used to refine the body of knowledge. Such refinements can include adding experiences, refining processes or adding to explanations and suggestions made to users. At the same time feedback on processes can include experiences and suggestions at each process steps and ways of improving activities at each step. These can be either ways to solve some problem, or steps in the business process.

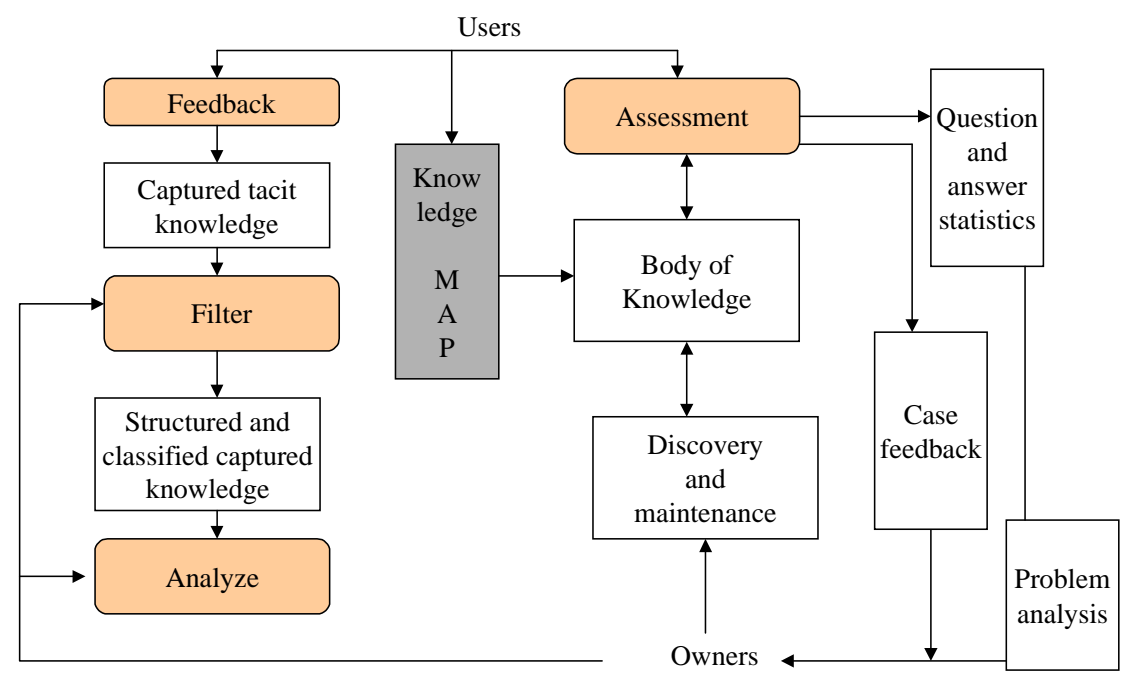

Figure 6 - Managing the Body of Knowledge

The portal structure shown in Figure 6 includes support for both objectivist or constructivist approach adopted. The feedback is provided by users and constantly analyzed to improve the structure of the body of knowledge. The feedback currently is through discussion databases that need to be analyzed to identify significant issues.

\section{An Example Portal}

Wade and Power (1998) identified interfaces as one of the important criteria for adoption of computer supported learning. Our approach has been to emphasize the idea of place that provides a community view and supports a selection of services. Currently we have been using a system, LiveNet, for this purpose. The approach is to emphasize collaboration through an entry interface that also provides access to the body of knowledge. The example portal is an initial prototype and so far concentrates on only part of the space shown in Figure 3. This particularly concerns the presentation and developing an understanding for objectivist learning while allowing group interaction for constructivist learning. Figure 7 illustrates the basic structure of this interface. It provides:

- the community governance structures through its roles,

- supports interaction through discussions, 
- contain any number of explicit documents, and

- supports group formation for constructivist learning.

It also provides awareness and notification features to alert community members to events important to them. The notifications can be customized to community needs. The interface shows all the information in the subject. It also provides different roles with different views. Thus for example the folder names 'information-to-tutors' can only be seen by tutors thus reducing the need for meetings and saving peoples time. The interface can then be used to enter the body of knowledge and use its associated knowledge services.

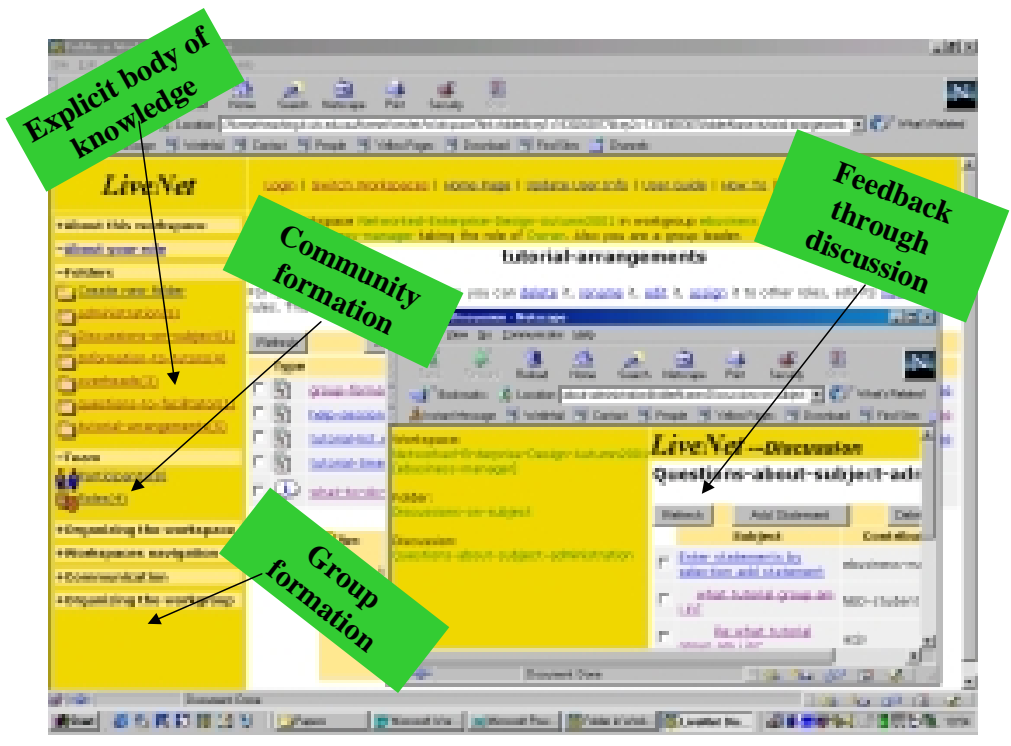

Figure 7 - A LiveNet collaborative services workspace

\section{Knowledge Maps}

The body of knowledge is accessed through a knowledge map. Knowledge maps show the concepts and relationships between them and can be accessed from any system. Thus they can be accessed from a community space like that in Figure 6 or specific items can be linked to specific business process steps. Figure 8 is a simple knowledge map used in this system. It is a linear list of terms, each of which leads to a concept screen that describes the concept and a self-assessment screen. Concept screens provide links to related concepts thus allowing the learner to navigate the map.

On selecting a concept or process step the user is presented with a description and can then follow up with some self-learning services. With concepts that refer to process steps, they can add to the concept by recording their experiences and interpretation of step guidelines.

\section{Self-learning}

This service, which is shown in Figure 9, allows learners to gain access to explanations of the concepts and examples of their

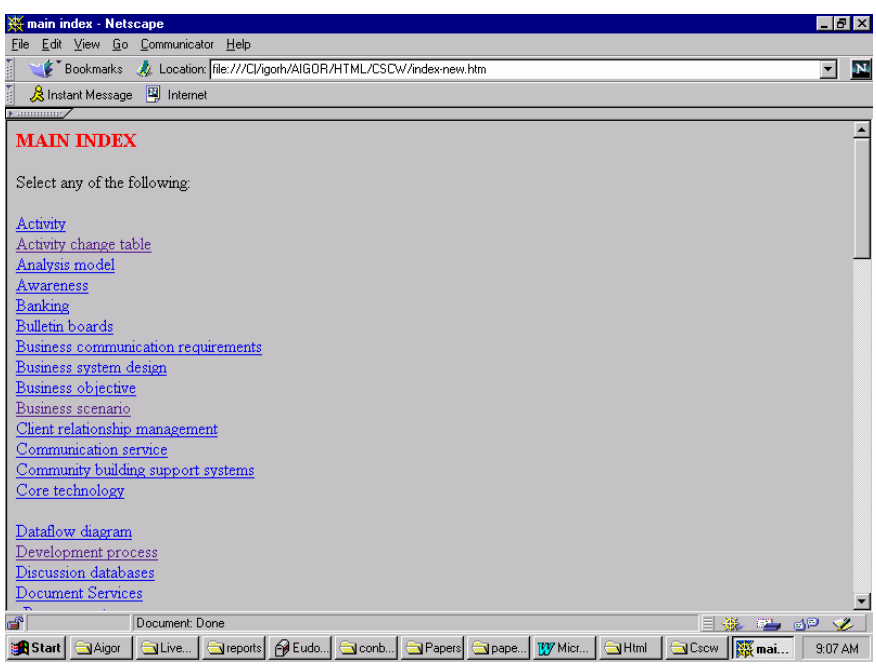

Figure 8 - A simple knowledge map 
use. Results provide feedback to owners of which concepts are best explained and which need additional support. It is of course possible at any time to post a question for further explanation by experts within the community. These feedback questions can be followed up with questions and discussions for further interpretation.

\section{Group Formation}

The interface in Figure 7 allows any members of the community of practice to form a group and make joint interpretations of situations within a business process. It is also possible for this group to be involved within a task in a business process and access the concept link to that step through the knowledge

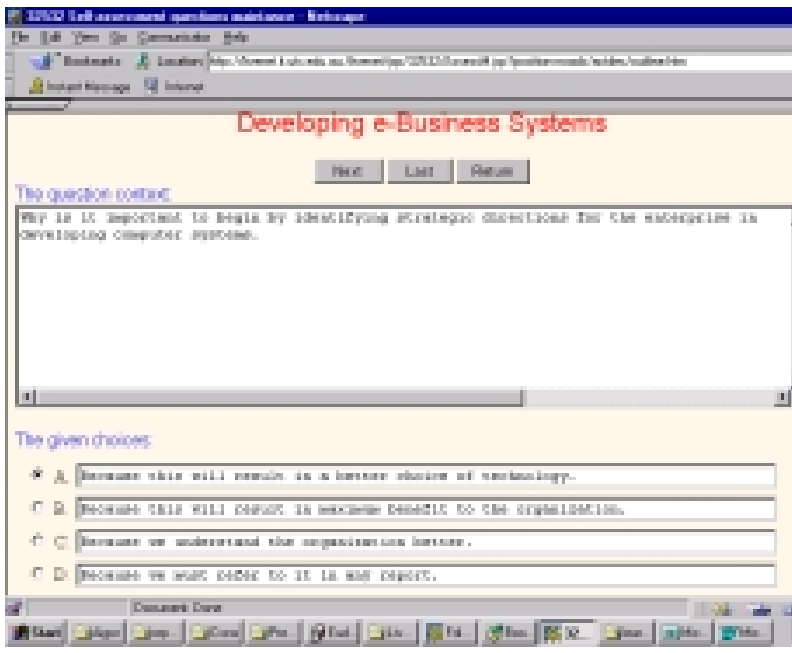

Figure 9 - A self-examination frame map. They can then use this to examine earlier experiences to determine their actions and further add to these experiences and any guidelines. Groups of novices can invite an expert to monitor their work.

\section{Introduction into Teaching}

The paper outlined the emergence of a variety of learning environments and the need for a way to set up workspaces to match the learning activities in these environments. It described such a portal, identified needed services and used a workspace paradigm to provide such services. Our work with workspaces so far has involved an average of 1000 students per semester.

\section{Some Experiences}

Lessons learned included design of workspaces to provide focused effort without the need of excessive navigation. Our earlier workspaces provided separate spaces for tutor assistance, case studies and overhead and administrative matters. The subsequent navigation led to some dissatisfaction and the creation of the workspace shown in Figure 6 proved much more acceptable. This provides access to all these services but governance features and folders allow us to focus information for particular roles. Over time we have developed the strategy shown in Figure 10 and very similar to that described by Salmon (2000). It introduces technology and learning in a gradual way. First there is some objectivist learning to describe what business processes using community workspaces. The next step is when the actual design process is introduced and students organized into groups to discuss design alternatives and make design choices. Correspondingly a project space is created in which such alternatives can be considered. Finally there is the prototype development where students choose technology to implement the design.

The strategy shown in Figure 10 also proved successful. This basically introduces technology in gradual stages. These begin with familiarization using the community interface in Figure 6, going on to the private group workspaces for developing project goals shown in Figure 8 and finally through students using the software to develop the prototype for a case study. In the case study students were given a number of milestones to aim for, starting with analysis, through design specification to setting up a prototype LiveNet system. Generally, these were successful in the sense that students understood the basic LiveNet modeling method and workspace description and set up prototypes with little effort. The social effect of this is to require students to pace their work according to the process rather, as is often the case, leaving it to the last minute. This has an obvious learning benefit although it is perceived as a nuisance by some students in that it requires them to follow a process. 
Experience with teaching in distant environments has led to some further observations. One difference that we have found is the necessity to "push" the process in a number of environments. This requires closer monitoring and driving by teachers.

\section{Summary}

The paper outlined the way teaching can be supported using knowledge portals. It outlined the structure of such portals stressing the need to support flexible governance structures and a variety of services. It then described a system that supports a combination of collaborative services and knowledge services.

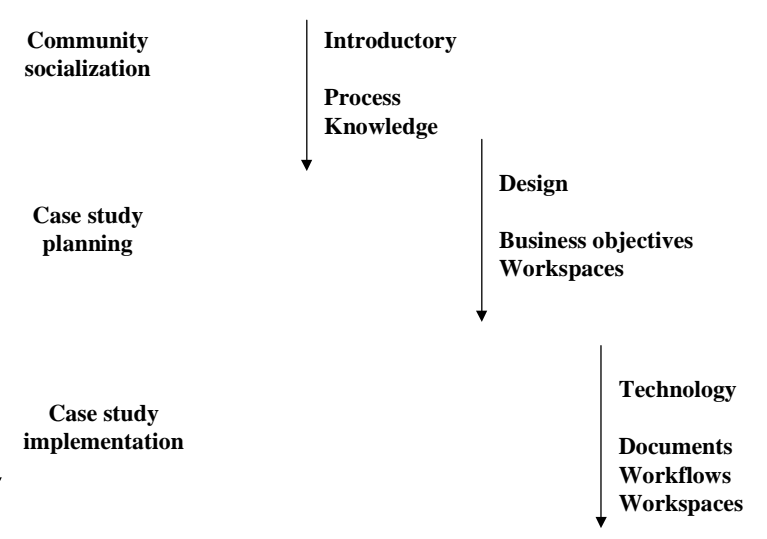

Figure 10 - The learning Process

\section{References}

Fischer, S. (2001): "Course and Exercise Sequencing using Metadata in Adaptive Hypermedia Learning Systems" ACM Journal of Educational Resources in Computing, Vol.1 No. 1, Spring, 2001, pp. 1-21.

Hawryszkiewycz (2000): "Evolving Knowledge Intensive Community Networks" Proceedings of Ausweb2000, Cairns, June 2000.

Nonaka, I. (1994): “A Dynamic Theory of Organizational Knowledge Creation” Organization Science, Vol. 5, No. 1, February, 1994, pp. 14-37.

Leidner, D.E. and Jarvenpaa, s. (1995): “The Information Age confronts education: A theoretical view” Information Systems Research, 4(1), pp. 24-54.

LiveNet - http://linus.socs.uts.edu.au/ 1gorh/workspace/explore/livenet.htm

Maedche, A. and Staab, S. (2001): "Ontology Learning for the Semantic Web” IEEE Intelligent Systems, Vol. 16, No.2, March=April, 2001, pp. 72-79.

Neal, L. (1997): "Virtual Classrooms and Communities" Group 97, Phoenix, Arizona, pp. 81-90.

Salmon, G. (2000): "E-Moderating: The Key to Teaching and Learning Online” Stylus Publishing, Sterling, VA.

Shank, R. (1998): "Horses for Courses" Communications of the ACM, 41(7), pp.23-25.

Wade, V.P. and Power, C. (1998): "Evaluating the Design and Delivery of WWW Based Educational Environments and Courseware" Proceedings of the $6^{\text {th }}$. Annual Conference on the Teaching of Computing, August 1998, Ireland, pp, 243248. 